\title{
ANALISIS RISIKO PADA TAHAP PELAKSANAAN KONSTRUKSI JALAN TOL CINERE - JAGORAWI, DEPOK
}

\author{
${ }^{1}$ Muhammad Faisal \\ ${ }^{2}$ Andi Tenrisukki Tenriajeng \\ Pasca Sarjana, Jurusan Teknik Sipil, Universitas Gunadarma, Indonesia \\ Email: muh.faisaal@gmail.com
}

\begin{abstract}
ABSTRAK
Tol Cinere-Jagorawi merupakan bagian dari Jakarta Outer Ring Road (JORR) II yang memiliki total panjang 110 kilometer yang mengelilingi Bandara Internasional Seokarta-Hatta hingga Tanjung Priok. Dengan adanya JORR II akan memudahkan akses dari pelabuhan ke bandara dan sebaliknya. Hal ini juga akan mengefisienkan arus lalu lintas dari barat ke timur mengingat lalu lintas di JORR I sudah terlalu banyak digunakan sehingga dapat menyebabkan kemacetan. Dalam setiap pembangunan Jalan Tol pasti ada resiko yang mungkin muncul. Untuk meminimalkan risiko yang dapat terjadi, identifikasi, analisis, mitigasi dan alokasi terhadap risiko yang mungkin terjadi - terutama risiko yang tergolong dalam kategori dominan - sangat penting. Hal ini diharapkan dapat menjadi dasar pengambilan keputusan oleh para pemangku kepentingan untuk menyelesaikan akibat negatif yang terjadi selama pembangunan Jalan Tol. Dalam penelitian ini, peneliti menggunakan penelitian deskriptif kualitatif dengan metode survei menggunakan kuesioner sebagai instrumen penelitian. Berdasarkan hasil kuisioner, terdapat 45 risiko yang teridentifikasi dalam penelitian ini. Setelah memperoleh hasil dari kuesioner, langkah selanjutnya adalah menentukan validitas dan reliabilitas, dan menganalisis penerimaan risiko untuk mengidentifikasi risiko mana yang tergolong sebagai faktor risiko dominan. Terdapat $8(18 \%)$ risiko yang tergolong Kategori Tidak Dapat Diterima dan 37 $(82 \%)$ risiko yang tergolong Kategori Tidak Diinginkan. Langkah selanjutnya adalah memitigasi risiko yang termasuk dalam faktor risiko dominan. Berdasarkan mitigasi risiko, manajemen risiko kepemilikan harus dilakukan oleh para pemangku kepentingan yang terlibat dalam pembangunan Jalan Tol.
\end{abstract}

Kata Kunci: Analisis Risiko, Identifikasi Risiko, Jalan Tol, Kepemilikan Risiko

\section{ABSTRACT}

Cinere-Jagorawi Toll Road is a part of Jakarta Outer Ring Road (JORR) II which has the total length of 110 kilometer that circle around Seokarta-Hatta International Airport until Tanjung Priok. By the existance of JORR II, there would be an easy access from seaport to airport and vice versa. This also would be streamlining traffic flow from west to east considering the traffic at JORR I has overused which could cause congestion. In every construction of the Toll Road, there would be some risks that possibly arise. To minimize the risks that could 
occur, identification, anlysis, mitigation and allocation towards the possible risks - especially the risks which are classified in dominant category - are essential. This is expected to be a basis of decision making by stakeolders to resolve negative consequences that happen during the construction of Toll Road. In this research, the researcher uses qualititive descriptive research with survey method using questionnaire as a research instrument. According to the result of questionnaire, there were 45 risks identified in this research. After acquiring the result from questionnaire, the next step were determining validity and reliability, and analysing the acceptance of the risks to identify which risks are classified as domminant risks factor. There were 8 (18\%) risks classified as Unacceptable Category and 37 (82\%) risks classified as Undesireble Category. The next step was mitigating the risks included in domminant risk factors. Based on risk mitigation, ownership risk management should be carried out by the stakeholeders involved in Toll Road construction.

Key word: Risk Analysis, Risk Identification, Toll Roads, Risk Ownership

\section{PENDAHULUAN}

Jalan tol adalah jalan umum yang merupakan bagian sistem jaringan jalan dan sebagai jalan nasional yang penggunanya diwajibkan membayar tol (Pasal 1 Peraturan Pemerintah No.15 Tahun 2005 Tentang Jalan Tol). Jalan Tol Cijago yang membentang dari Cimanggis hingga Cinere sepanjang 14,6 kilometer merupakan bagian dari jaringan Jalan Tol Jakarta Outer Ring Road (JORR) II sepanjang lebih dari 110 kilometer yang melingkar dari Bandara Internasional Soekarno-Hatta hingga Tanjung Priok. Jaringan Jalan Tol JORR II merupakan lingkaran kedua dari jaringan JORR. Jalan Tol Cijago akan menghubungkan wilayah barat Jakarta dengan wilayah Tangerang yang kemudian dilanjutkan dari simpang susun di Kunciran ke Bandara Internasional Soekarno-Hatta sepanjang 55,73 kilometer. Ruas tol Cijago berfungsi sebagai peningkatan fasilitas sarana transportasi untuk memperlancar lalu lintas dan meningkatkan pelayanan distribusi barang dan jasa guna menunjang pertumbuhan ekonomi antar wilayah.

\section{METODE PENELITIAN}

Penelitian dilakukan pada Proyek pembangunan jalan tol Cinere - Jagorawi dengan metode penelitian deskriptif kualitatif. Metode deskriptif kualitatif bertujuan untuk membuat deskripsi, gambaran atau lukisan secara sistematik, faktual dan akurat mengenai fenomena atau hubungan antar fenomena yang akan di selidiki. Metode yang digunakan dalam penelitian deskriptif kualitatif adalah dengan penelitian lapangan dengan berpedoman kepada kajian pustaka dan data penunjang yang ada serta penelitian-penelitian sebelumnya. Permasalahan yang ada diperoleh dengan metode wawancara, merujuk pada penelitian sebelumnya dan survei untuk mendapatkan pendapat atau opini dari responden dan expert mengenai kemungkinan risiko yang akan terjadi. 

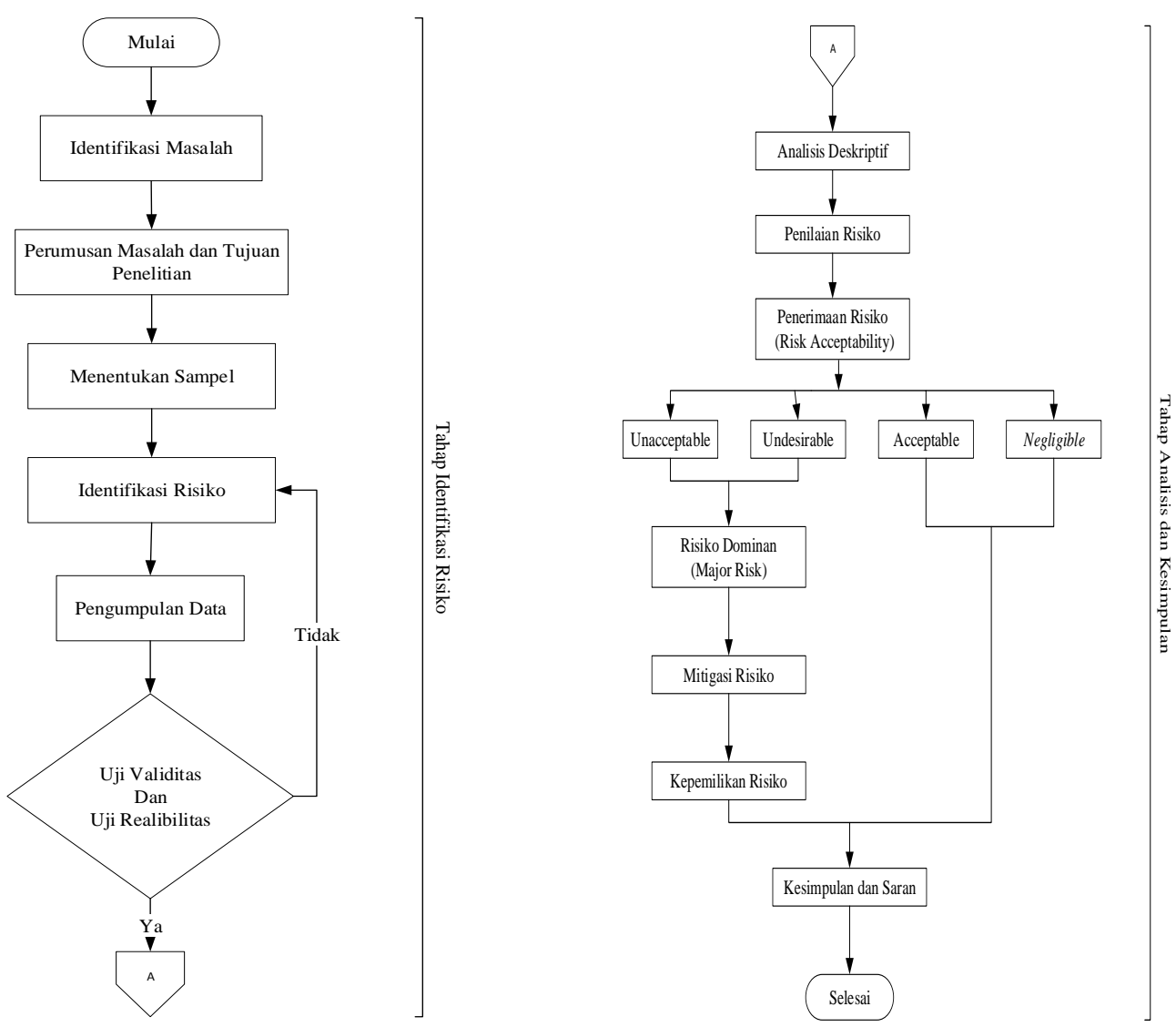

Gambar 1. Flowchart Penelitian (analisis, 2018)

\section{TINJAUAN PUSTAKA}

\section{Analisis Risiko}

Analisis risiko merupakan suatu proses dari identifikasi dan penilaian (assessment), sedangkan manajemen risiko adalah respon dan tindakan yang dilakukan untuk memitigasi serta mengontrol risiko yang telah dianalisis (Thompson and Perry, 1991).

\section{Identifikasi Risiko}

Identifikasi isiko merupakan proses penganalisisan untuk menemukan secara sistematis dan secara berkesinambungan risiko (kerugian yang potensial) yang menantang perusahaan (Darmawi, 2006). Identifikasi risiko merupakan tahap awal dalam manajemen risiko yang bertujuan untuk dapat menguraikan dan merinci jenis risiko yang mungkin terjadi dari aktivitas atau kegiatan yang akan kita lakukan.

\section{Klasifikasi Risiko}

Berdasarkan konsekuensi, risiko dapat diklasifikasikan berdasarkan frekuensi kejadian, akibat risiko dan kemungkinan. Menurut jenisnya, risiko diklasifikasikan menjadi risiko murni dan risiko spekulatif.

\section{Penilaian Risiko}

Penilaian risiko pada dasarnya adalah melakukan perhitungan atau penilaian terhadap dampak risiko yang telah teridentifikasi, besar kecilnya dampak risiko akan dapat 
dikategorikan, mana merupakan risiko dengan tingkat yang utama (major risks), yang mempunyai dampak besar dan luas yang membutuhkan pengelolaan, atau tidak (minor risks), yang tidak memerlukan penanganan khusus karena tingkat risiko ada dalam batasbatas yang dapat diterima. Godfrey, (1996) menguraikan besarnya dampak risiko merupakan perkalian dari frekuensi (likelihood) dengan konsekuensi (consequence) dari risiko yang telah teridentifikasi.

\section{Penerimaan Risiko}

Analisis terhadap penerimaan risiko (Risk Acceptability) ditentukan berdasarkan nilai risiko yang diperoleh dari hasil perkalian antara kemungkinan (likelihood) dengan konsekuensi (concequense) risiko.

Tabel 1. Penilaian Tingkat Penerimaan Risiko (Assesment of Risk Acceptability) (Godfrey, 1996)

\begin{tabular}{|c|c|c|c|c|c|}
\hline \multicolumn{6}{|c|}{ ASSESSMENT OF RISK ACCEPTABILITY } \\
\hline & $\begin{array}{c}\text { Catastropic } \\
\text { (Sangat } \\
\text { Besar) } \\
\text { (5) }\end{array}$ & $\begin{array}{c}\text { Critical } \\
\text { (Besar) } \\
(4)\end{array}$ & $\begin{array}{c}\text { Serious } \\
\text { (Sedang) } \\
(3)\end{array}$ & $\begin{array}{c}\text { Marginal } \\
\text { (Kecil) } \\
\text { (2) }\end{array}$ & $\begin{array}{c}\text { Negligible } \\
\text { (Sangat } \\
\text { Kecil) } \\
\text { (1) }\end{array}$ \\
\hline $\begin{array}{c}\text { Frequent } \\
\text { (Sangat } \\
\text { Sering) } \\
\text { (5) }\end{array}$ & $\begin{array}{c}\text { Unacceptable } \\
\text { (25) }\end{array}$ & $\begin{array}{c}\text { Unacceptable } \\
\text { (20) }\end{array}$ & $\begin{array}{c}\text { Unacceptable } \\
\text { (15) }\end{array}$ & $\begin{array}{c}\text { Undesirable } \\
\text { (10) }\end{array}$ & $\begin{array}{c}\text { Undesirable } \\
\text { (5) }\end{array}$ \\
\hline $\begin{array}{c}\text { Probable } \\
\text { (Sering) } \\
\text { (4) }\end{array}$ & $\begin{array}{c}\text { Unacceptable } \\
\text { (20) }\end{array}$ & $\begin{array}{c}\text { Unacceptable } \\
\text { (16) }\end{array}$ & $\begin{array}{c}\text { Undesirable } \\
\text { (12) }\end{array}$ & $\begin{array}{c}\text { Undesirable } \\
\text { (8) }\end{array}$ & $\begin{array}{c}\text { Acceptable } \\
\text { (4) }\end{array}$ \\
\hline $\begin{array}{c}\text { Occasional } \\
\text { (Kadang- } \\
\text { kadang) } \\
\text { (3) }\end{array}$ & $\begin{array}{c}\text { Unacceptable } \\
\text { (15) }\end{array}$ & $\begin{array}{c}\text { Undesirable } \\
\text { (12) }\end{array}$ & $\begin{array}{c}\text { Undesirable } \\
\text { (9) }\end{array}$ & $\begin{array}{c}\text { Undesirable } \\
\text { (6) }\end{array}$ & $\begin{array}{c}\text { Acceptable } \\
\text { (3) }\end{array}$ \\
\hline $\begin{array}{c}\text { Remote } \\
\text { (Jarang) } \\
(2)\end{array}$ & $\begin{array}{c}\text { Undesirable } \\
\text { (10) }\end{array}$ & $\begin{array}{c}\text { Undesirable } \\
\text { (8) }\end{array}$ & $\begin{array}{c}\text { Undesirable } \\
\text { (6) }\end{array}$ & $\begin{array}{c}\text { Acceptable } \\
\text { (4) }\end{array}$ & $\begin{array}{c}\text { Negligible } \\
\text { (2) }\end{array}$ \\
\hline $\begin{array}{c}\text { Improbable } \\
\text { (Sangat } \\
\text { Jarang) } \\
\text { (1) }\end{array}$ & $\begin{array}{c}\text { Undesirable } \\
\text { (5) }\end{array}$ & $\begin{array}{c}\text { Acceptable } \\
\text { (4) }\end{array}$ & $\begin{array}{c}\text { Acceptable } \\
\text { (3) }\end{array}$ & $\begin{array}{c}\text { Negligible } \\
\text { (2) }\end{array}$ & $\begin{array}{c}\text { Negligible } \\
\text { (1) }\end{array}$ \\
\hline & Description & & Guidc & & \\
\hline Key & Unacceptable & Tidak dap & diterima, harus & dihilangkan atc & ditranfer \\
\hline & Undesirable & & dak diharapkan & harus dihindar & \\
\hline
\end{tabular}




\begin{tabular}{|ll|}
\hline Acceptable & Dapat diterima \\
\cline { 2 - 2 } & \\
\hline Negligible & Dapat diabaikan \\
\hline
\end{tabular}

\section{HASIL \& PEMBAHASAN}

Berdasarkan hasil analisis yang telah dilakukan, maka didapatkan hasil sebagai berikut.

\section{Sumber Risiko}

Risiko yang teridentifikasi pada tahap pelaksanaan konstruksi jalan tol Cinere-Jagorawi berjumlah 45 (empat puluh lima) risiko. Menurut kategori risiko yang paling banyak adalah risiko teknis, yaitu sebanyak 18 risiko atau $40 \%$ dari total kesuluruhan risiko yang teridentifikasi. Presentase jumlah risiko dapat dilihat di tabel 2.

Tabel 2. Presentase Jumlah Risiko Berdasarkan Sumber Risiko (Analisis, 2018)

\begin{tabular}{|cccc|}
\hline No. & Risiko & Jumlah & Prosentase (\%) \\
\hline 1 & Alami & 2 & 4.44 \\
\hline 2 & Teknis & 18 & 40 \\
\hline 3 & Manusia & 5 & 11.11 \\
\hline 4 & Kriminal & 3 & 6.67 \\
\hline 5 & Keselamatan & 2 & 4.44 \\
\hline 6 & Politis & 4 & 8.89 \\
\hline 7 & Lingkungan & 3 & 6.67 \\
\hline 8 & Ekonomi & 3 & 6.67 \\
\hline 9 & Keuangan & 5 & 11.11 \\
\hline & Jumlah & 45 & 100 \\
\hline
\end{tabular}

\section{Jawaban Responden Terhadap Kemungkinan (Likehood)}

Frekuensi terjadinya risiko pada skala 2 (jarang) paling banyak muncul, yang kemunculannya mencapai 69\%. Untuk skala 1 (sangat jarang) dan skala 5 sangat sering berjumlah 0 risiko, ini artinya responden berpendapat bahwa tidak ada risiko yang frekuensinya seperti itu, jadi semua risiko itu tidak ada yang sangat sering, maupun sangat jarang.

Tabel 3. Frekuensi Kemungkinan (likelihood) Risiko (Analisis, 2018)

\begin{tabular}{|c|c|}
\hline Skala & Jumlah Risiko \\
\hline Frekuensi skala 1 (sangat Jarang) & 0 \\
\hline Frekuensi skala 2 (jarang) & 31 \\
\hline Frekuensi skala 3 (kadang-kadang) & 6 \\
\hline Frekuensi skala 4 (sering) & 8 \\
\hline Frekuensi skala 5 (sangat sering) & 0 \\
\hline
\end{tabular}




\section{Tabel Risiko Dominan (Major Risk)}

Risiko-risiko yang bersifat dominan (major risk) adalah risiko-risiko yang termasuk kategori unacceptable (risiko yang tidak dapat diterima) dan risiko-risiko yang termasuk kategori undesirable (risiko yang tidak diharapkan). Risiko-risiko ini merupakan risiko dengan risk acceptability nilai perkalian likehood dan consequences sama dengan atau diatas 5 (lima). Keberadaan risiko-risiko dominan (major risk) akan berpengaruh besar pada pelaksanaan pembangunan jalan tol Cinere-Jagorawi.

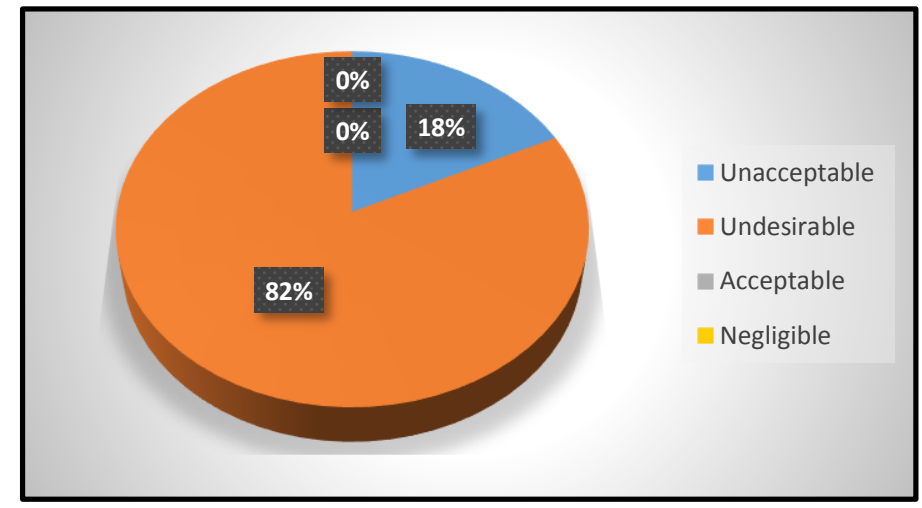

Gambar 2. Tingkat Penerimaan Risiko (Risk Acceptability) (analisis, 2018)

Dari 45 risiko yang teridentifikasi, 45 risiko masuk dalam kategori risiko dominar yang prosentasenya $100 \%$, jadi bisa dikatakan bahwa proyek pembangunan jalan tol CinereJagorawi ini adalah proyek pemabangunan yang berisiko tinggi (High Risk), karena semua risiko yang teridentifikasi merupakan risiko dominan sehingga haru mendapatkan perhatian khusus. Data dan persentase diatas maka dijabarkan mengenai risiko-risiko dominan (major risk) yang teridentifikasi yaitu risiko dengan kategori Unacceptable (tidak dapat diterima) dan risiko kategori Undesirable (tidak diharapkan) yang selanjutnya akan dilakukan tindakan mitigasi.

Tabel 4. Distribusi Penerimaan Risiko untuk Setiap Sumber Risiko (Analisis, 2018)

\begin{tabular}{|cccccccccccc|}
\hline \multirow{2}{*}{$\begin{array}{c}\text { Sumber } \\
\text { Risiko }\end{array}$} & \multicolumn{2}{c}{$\begin{array}{c}\text { Identifikasi } \\
\text { Risiko }\end{array}$} & \multicolumn{7}{c|}{ Tingkat Penerimaan Risiko } \\
\cline { 3 - 11 } & $\mathrm{Jml}$ & $\%$ & $\mathrm{Jml}$ & $\%$ & $\mathrm{jml}$ & $\%$ & $\mathrm{jml}$ & $\%$ & $\mathrm{jml}$ & $\%$ \\
\hline Alami & 2 & 4.44 & 1 & 2.22 & 1 & 2.22 & 0 & 0 & 0 & 0 \\
\hline Teknis & 18 & 40 & 1 & 2.22 & 17 & 37.78 & 0 & 0 & 0 & 0 \\
\hline Manusia & 5 & 11.11 & 0 & 0 & 5 & 11.11 & 0 & 0 & 0 & 0 \\
\hline Kriminal & 3 & 6.67 & 0 & 0 & 3 & 6.67 & 0 & 0 & 0 & 0 \\
\hline Keselamatan & 2 & 4.44 & 1 & 2.22 & 1 & 2.22 & 0 & 0 & 0 & 0 \\
\hline Politis & 4 & 8.89 & 1 & 2.22 & 3 & 6.67 & 0 & 0 & 0 & 0 \\
\hline Lingkungan & 3 & 6.67 & 2 & 4.44 & 1 & 2.22 & 0 & 0 & 0 & 0 \\
\hline Ekonomi & 3 & 6.67 & 2 & 4.44 & 1 & 2.22 & 0 & 0 & 0 & 0 \\
\hline Keuangan & 5 & 11.11 & 0 & 0 & 5 & 11.11 & 0 & 0 & 0 & 0 \\
\hline Jumlah & 45 & 100 & 8 & & 37 & & 0 & 0 & \\
\hline Presentase & 100 & & & 17.78 & & 82.22 & & 0 & \\
\hline
\end{tabular}


Tabel Risiko yang termasuk Tidak dapat diterima (Unacceptable) sebanyak 8 (delapan) risiko dan presentasenya adalah $17.78 \%$, risiko-risiko yang mempunyai tingkat penerimaan risiko paling tinggi adalah Adanya penolakan dari ormas-ormas tertentu demi kepentingan golongannya, dan sulitnya pembebasan lahan untuk pembangunan jalan tol. Kedua risiko itu memiliki nilai risiko yang paling tinggi yaitu 20 (dua puluh). Risiko yang masuk dalam kategori tidak diharpkan (Undesirable) sebanyak

37 (tiga puluh tujuh) risiko dan presentasenya adalah $82.22 \%$, sumber risiko yang paling banyak masuk dalam kategori tidak diharapkan adalah risiko teknis yang berjumlah 17 (tujuh belas) risiko dan presentasenya adalah $37.78 \%$. kategori dapat diterima (Acceptable) berjumlah 0 (nol) risiko, dan kategori dapat diabaikan (Negligible) berjumlah 0 (nol) risiko, ini menandakan semua risiko berpotensi menganggu kelancaran proyek dan semua risiko perlu dimitigasi.

\section{Mitigasi Risiko (Risk Mitigation)}

Risiko-risiko dominan (major risk) akan memberikan pengaruh yang sangat besar pada pelaksanaan pembangunan jalan tol Cinere-Jagorawi. Risiko- risiko yang termasuk dalam kategori risiko yang tidak dapat diterima (unacceptable) dan risiko yang masuk dalam kategori tidak diharapkan (undesirable) memerlukan adanya tindakan mitigasi untuk mengurangi dampak yang ditimbulkan. Tindakan mitigasi untuk risiko-risiko yang termasuk dalam kategori tidak dapat diterima (unacceptable) dapat dilihat pada tabel dibawah ini.

Tabel 5. Mitigasi Risiko Unacceptable (Analisis, 2018)

\begin{tabular}{|c|c|c|c|c|}
\hline $\begin{array}{l}\text { No } \\
\text { Risiko }\end{array}$ & Identifikasi Risiko & $\begin{array}{l}\text { Nilai } \\
\text { Risiko }\end{array}$ & $\begin{array}{l}\text { Penerimaan } \\
\text { Risiko }\end{array}$ & Mitigasi Risiko \\
\hline I & ALAMI & & & \\
\hline \multirow[t]{2}{*}{1} & \multirow[t]{2}{*}{$\begin{array}{l}\text { Keterlamabatan proyek } \\
\text { akibat cuaca (hujan, dls) }\end{array}$} & \multirow[t]{2}{*}{16} & \multirow[t]{2}{*}{ Unacceptable } & $\begin{array}{l}\text { Menjadwalkan terlebih dahulu } \\
\text { pelaksanaan pekerjaan sebelum } \\
\text { ada hujan dan untuk perencanaan } \\
\text { jadwal pekerjaannya ditambah } \\
\text { waktunya agar pada saat hujan } \\
\text { progres pekerjaan tidak terhambat }\end{array}$ \\
\hline & & & & $\begin{array}{c}\text { Menambah jam kerja setiap } \\
\text { harinya }\end{array}$ \\
\hline II & TEKNIS & & & \\
\hline \multirow[t]{2}{*}{20} & \multirow{2}{*}{$\begin{array}{c}\text { Data yang diberikan } \\
\text { owner kurang lengkap, } \\
\text { sehingga design berubah- } \\
\text { ubah pada saat } \\
\text { pelaksanaan proyek }\end{array}$} & \multirow[t]{2}{*}{16} & \multirow[t]{2}{*}{ Unacceptable } & $\begin{array}{l}\text { Koordinasi dengan perencana dari } \\
\text { pihak owner, jadi sebelum } \\
\text { pekerjaan dimulai semua data } \\
\text { harus sudah lengkap }\end{array}$ \\
\hline & & & & $\begin{array}{l}\text { Melakukan review desain untuk } \\
\text { meyesuaikan kondisi di lapangan }\end{array}$ \\
\hline $\mathbf{V}$ & KESELAMATAN & & & \\
\hline \multirow[t]{2}{*}{30} & \multirow{2}{*}{$\begin{array}{l}\text { Kurangnya kesadaran } \\
\text { pekerja proyek akan } \\
\text { keselamatan dan } \\
\text { keamanan di lingkungan } \\
\text { proyek }\end{array}$} & \multirow[t]{2}{*}{16} & \multirow[t]{2}{*}{ Unacceptable } & $\begin{array}{c}\text { Mengadakan pengarahan dan } \\
\text { penyadaran akan pentingnya } \\
\text { Kesehatan dan Keselamatan Kerja } \\
\text { (K3) }\end{array}$ \\
\hline & & & & $\begin{array}{c}\text { Mengadakan Safety Morning Talk } \\
\text { setiap pagi sebelum memulai } \\
\text { pekerjaan }\end{array}$ \\
\hline
\end{tabular}


JURNAL KACAPURI

JURNAL KEILMUAN TEKNIK SIPIL

Volume 4 Nomor 2 Edisi Desember 2021

\begin{tabular}{|c|c|c|c|c|}
\hline VI & POLITIS & & & \\
\hline \multirow[b]{2}{*}{34} & \multirow{2}{*}{$\begin{array}{l}\text { Adanya penolakan dari } \\
\text { ormas-ormas tertentu } \\
\text { demi kepentingan } \\
\text { golongannya }\end{array}$} & \multirow[b]{2}{*}{20} & \multirow[b]{2}{*}{ Unacceptable } & $\begin{array}{l}\text { Melakukan koordinasi dengan } \\
\text { berbagai pihak keamanan, baik itu } \\
\text { dari pemerintahan maupun dari } \\
\text { ormas sekitar }\end{array}$ \\
\hline & & & & $\begin{array}{c}\text { Rutin engadakan sosialisasi } \\
\text { mengenai proyek kepada seluruh } \\
\text { elemen masyarakat sehingga tidak } \\
\text { terjadi pro dan kontra pada saat } \\
\text { pekerjaan dimulai }\end{array}$ \\
\hline VII & LINGKUNGAN & & & \\
\hline \multirow{6}{*}{35} & \multirow{6}{*}{$\begin{array}{l}\text { Sulitnya pembebasan } \\
\text { lahan untuk } \\
\text { pembangunan jalan tol }\end{array}$} & \multirow{6}{*}{20} & \multirow{6}{*}{ Unacceptable } & $\begin{array}{c}\text { Melalukan negosiasi dengan } \\
\text { pemilik tanah perihal harga ganti } \\
\text { rugi tanah (harga tanah boleh } \\
\text { lebih tinggi dari Nilai Jual Objek } \\
\text { Pajak) }\end{array}$ \\
\hline & & & & $\begin{array}{c}\text { Rutin melakukan sosialisasi ke } \\
\text { masyarakat akan manfaat dari } \\
\text { proyek yang sedang dikerjakan }\end{array}$ \\
\hline & & & & $\begin{array}{l}\text { Mengajak tokoh masyarakat } \\
\text { untuk turut serta } \\
\text { mensosialisasikan manfaat dari } \\
\text { proyek yang sedang dikerjakan }\end{array}$ \\
\hline & & & & $\begin{array}{c}\text { Mengantisipasi adanya calo } \\
\text { tanah/perantara yang akan } \\
\text { berdampak pada tingginya biaya } \\
\text { pembebsan lahan }\end{array}$ \\
\hline & & & & $\begin{array}{l}\text { Dana yang dialokasikan untuk } \\
\text { pembebasan lahan harus siap agar } \\
\text { pembayaran kepada masyarakat } \\
\text { sekitar tidak terlambat }\end{array}$ \\
\hline & & & & $\begin{array}{c}\text { Bekerjasama dengan } \\
\text { Pemerintahan lokal seperti } \\
\text { kecamatan, kelurahan, RW/RT } \\
\text { disekitar lokasi jalan tol dalam } \\
\text { rangka pencatatan lahan } \\
\text { masyarakat untuk mengantisipasi } \\
\text { adanya lahan yang masih } \\
\text { bersengketa atau belum jelas } \\
\text { kepemilikan tanahnya }\end{array}$ \\
\hline \multirow{2}{*}{37} & \multirow{2}{*}{$\begin{array}{c}\text { Dana yang diminta } \\
\text { masyarakat sekitar terlalu } \\
\text { besar, sehingga } \\
\text { mengganggu kelancaran } \\
\text { proyek }\end{array}$} & \multirow[t]{2}{*}{16} & \multirow[t]{2}{*}{ Unacceptable } & $\begin{array}{c}\text { Rutin mengadakan sosialisasi } \\
\text { kepada masyrakat akan manfaat } \\
\text { dari proyek ini terhadap } \\
\text { masyarakat sekitar }\end{array}$ \\
\hline & & & & $\begin{array}{l}\text { Melakukan negosiasi ulang agar } \\
\text { mencapai nilai kesepakatan kedua } \\
\text { belah pihak }\end{array}$ \\
\hline VIII & EKONOMI & & & \\
\hline 39 & $\begin{array}{l}\text { Terjadinya kenaikan } \\
\text { harga BBM pada saat }\end{array}$ & 16 & Unacceptable & $\begin{array}{l}\text { Membuat perhitungan biaya } \\
\text { preliminary dan memasukan }\end{array}$ \\
\hline
\end{tabular}




\begin{tabular}{|c|c|c|c|c|}
\hline & proyek masih berjalan & & & $\begin{array}{c}\text { faktor kenaikan harga BBM } \\
\text { sebelum memulai pekerjaan }\end{array}$ \\
\cline { 3 - 5 } & & $\begin{array}{c}\text { Menerapkan upaya penghematan } \\
\text { BBM serta menggunakan alat } \\
\text { berat yang menggunakan BBM } \\
\text { dengan lebih efisien }\end{array}$ \\
\hline 40 & $\begin{array}{c}\text { Terjadinya inflasi pada } \\
\text { saat proyek } \\
\text { pembangunan jalan tol } \\
\text { masih berjalan }\end{array}$ & 16 & Unacceptable & $\begin{array}{c}\text { Manajemen persediaan material } \\
\text { proyek lebih ditingkatkan } \\
\text { terutama material yang } \\
\text { membutuhkan jumlah yang besar } \\
\text { untuk menghindari terjadinya } \\
\text { inflasi }\end{array}$ \\
\hline
\end{tabular}

\section{Kepemilikan Risko (Ownership of the Risk)}

Risiko-risiko yang masuk dalam kategori dominan, dialokasikan kepemilikan risiko kepada masing-masing pihak yang terlibat dalam pelaksanaan pembangunan jalan tol Cinere-Jagorawi yaitu pemilik proyek (Owner), Kontraktor Pelaksana dan Konsultan Perencana. Masing-masing pihak ini memiliki tanggung jawab dan dapat menangani setiap risiko yang muncul. Alokasi kepemilikan risiko ini didasarkan pada tanggung jawab, pengendalian dan penanganan dari risiko-risiko yang terjadi.

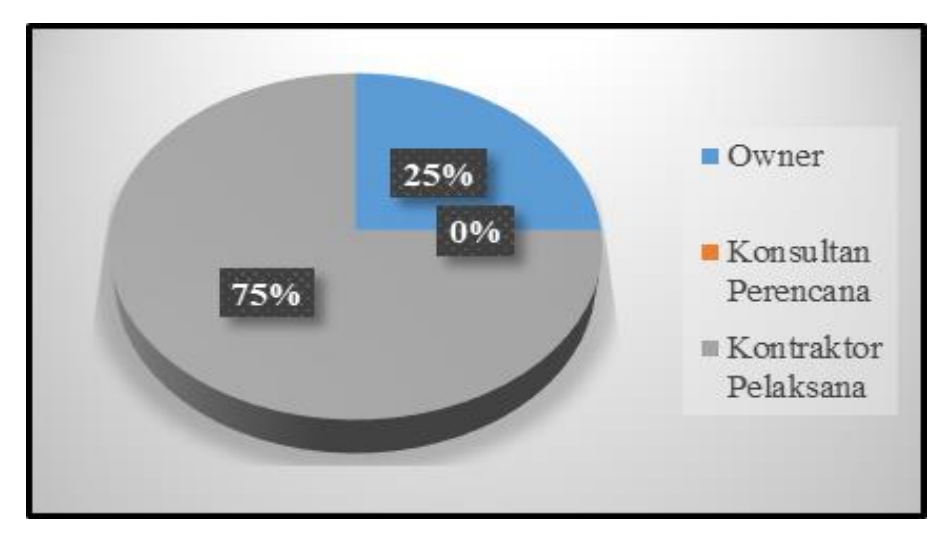

Gambar 3. Presentase Kepemilikan Risiko Kategori Unacceptable (analisis, 2018)

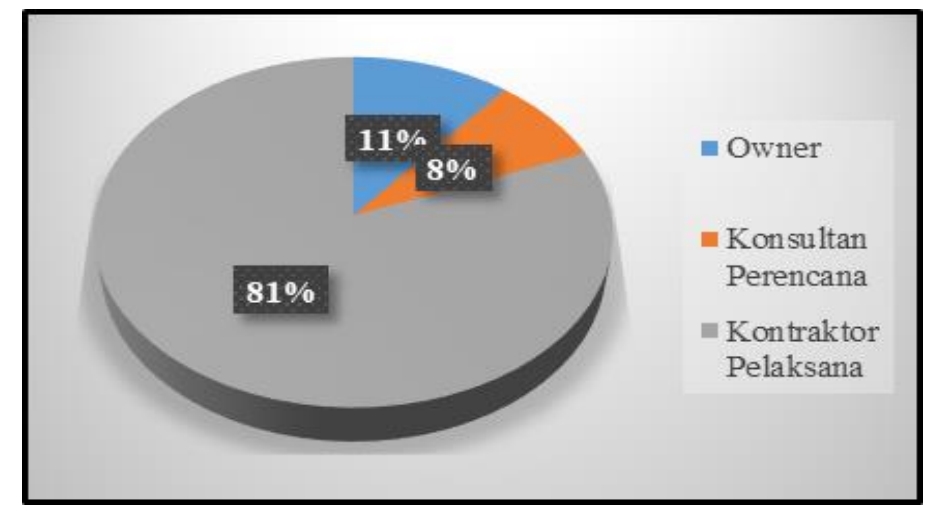

Gambar 4. Presentase Kepemilikan Risiko Kategori Undesirable (analisis, 2018) 
Kepemilikan risiko (ownership of risk) untuk risiko-risiko dominan (major risk) pada proyek Jalan tol Cinere-Jagorawi terlihat bahwa kepemilikan risiko terbesar adalah milik kontraktor pelaksana sebagai pelaksana proyek dengan 6 risiko unacceptable dan 30 risiko undesirable. Kepemilikan risiko terbesar menjadi tanggung jawab kontraktor, hal ini karena sebagian besar identifikasi risiko adalah risiko yang terjadi pada tahap pelaksanaan konstruksi.

\section{PENUTUP}

\section{Kesimpulan}

Berdasarkan hasil penelitian dan analisis yang telah dilakukan, maka penulis dapat menyampaikan kesimpulan sebagai berikut:

1. Pada pelaksanaan pembangunan jalan tol Cinere-Jagorawi teridentifikasi 45 (empat puluh lima) risiko berdasarkan aktivitas pada tahap pelaksanaan proyek. Risiko-risiko yang teridentifikasi terdapat 2 (dua) risiko, 18 (delapan belas) risiko Teknis, 5 (lima) risiko manusia, 3 (tiga) risiko kriminal, 2 (dua) risiko keselamatan, 4 (empat) risiko politis, 3 (tiga) risiko lingkungan, 3 (risiko) ekonomi, dan 5 (lima) risiko keuangan. Dari risiko-risiko yang teridentifikasi dilakukan analisis penerimaan risiko (assessment of risk) yang menunjukkan terdapat 8 (delapan) risiko yang termasuk dalam kategori tidak dapat diterima (unacceptable), 37 (tiga puluh tujuh) risiko yang masuk dalam kategori tidak diharapkan (undesirable), 0 (nol) risiko yang masuk kategori dapat diterima (acceptable), dan 0 (nol) risiko yang masuk kategori dapat diabaikan (negligible).

2. Semua risiko-risiko yang teridentifikasi pada proyek pembangunan jalan tol Cinere-Jagorawi termasuk dalam risiko dominan (major risk) yaitu sebanyak 45 (empat puluh lima) risiko yang terdiri dari 8 (delapan) risiko yang tidak dapat diterima (unacceptable) salah satunya adalah sulitnya pembebasan lahan untuk pembangunan jalan tol. Risiko yang termasuk dalam kategori unacceptable ini harus mendapat perhatian khusus karena apabila tidak ditangani dengan baik akan berdampak besar terhadap proyek. Risiko dengan kategori tidak diharapkan (undesirable) sebanyak 37 (tiga puluh tujuh) risiko dengan risiko terbanyak berasal dari risiko teknis seperti Ketidaksesuaian design perencanaan dengan lapangan, dan Treatment tanah tidak sesuai standar. Risiko yang masuk dalam kategori undesirable ini juga harus mendapatkan perhatian khusus karena dapat berdampak buruk pada pelaksanaan proyek.

3. Tindakan mitigasi risiko dilakukan untuk mengurangi dampak negatif dari risiko-risiko yang termasuk dalam kategori risiko dominan (major risk). Untuk risiko yang termasuk kategori tidak dapat diterima (unacceptable) dilakukan 19 (Sembilan belas) tindakan mitigasi salah satunya adalah tindakan mitigasi untuk risiko Sulitnya pembebasan lahan untuk pembangunan jalan tol yaitu dengan Melalukan negosiasi dengan pemilik tanah perihal harga ganti rugi tanah (harga tanah boleh lebih tinggi dari Nilai Jual Objek Pajak). Sedangkan risiko yang termasuk dalam kategori tidak diharapkan (undesirable) dilakukan 55 (lima puluh lima) tindakan mitigasi salah satunya adalah tindakan mitigasi untuk risiko Hilangnya material dan peralatan selama proyek berlangsung yaitu dengan Memperketat akses masuk 
dan akses keluar dari dan ke lokasi proyek dan menempatkan petugas keamanan khusus untuk mencegah adanya praktek pencurian.

4. Kepemilikan risiko (ownership of risk) dalam pelaksanaan pembangunan jalan tol Cinere-Jagorawi yaitu Owner, konsultan perencana, dan kontraktor pelaksana. Kepemilikan risiko dilakukan agar risiko-risiko yang ada dapat ditangani dengan baik oleh pihak-pihak yang bertanggung jawab dalam risiko-risiko yang termasuk dalam kategori risiko dominan (major risk). Dari hasil penelitian menunjukkan untuk risiko yang termasuk dalam kategori unacceptable terdapat 2 (dua) risiko yang menjadi tanggung jawab owner, dan 6 (enam) risiko yang menjadi tanggung jawab kontraktor pelaksana. Hal ini menunjukkan bahwa kontraktor adalah pihak yang paling banyak bertanggung jawab terhadap risiko-risiko yang timbul. Sedangkan untuk risiko yang termasuk dalam kategori undesirable terdapat 4 (empat) risiko yang menjadi tanggung jawab owner, 3 (tiga) risiko yang menjadi tanggung jawab konsultan perencana, dan 30 (tiga puluh) risiko yang menjadi tanggung jawab kontraktor pelaksana. Kepemilikan risiko undesirable terbesar menjadi tanggung jawab kontraktor karena sebagian besar identifikasi risiko adalah risiko yang terjadi pada tahap pelaksanaan pekerjaan.

\section{DAFTAR PUSTAKA}

AASHTO, 2001. A Policy on Geometric Design of Highways and Streets

Anonim. Undang-Undang Republik Indonesia, Nomor 38 Tahun 2004, Tentang Jalan.

Ari S dan Niko S. 2013. "Analisis Risiko Jalan Tol Tahap Pra Konstruksi (Studi Kasus Jalan Tol Pekanbaru-Dumai)" (Jurnal). Riau; Universitas Riau

Cooper, D.R., dan Schindler, P.S., 2006. business Research Methods. Eight Edition. McGrawHill/Irwin, New York, NY 10020.

Darmawi, H. 2006. Manajemen Risiko. Cetakan kesepuluh. Jakarta : Bumi Aksara.

Eriyanto. 2007. Teknik Sampling Analisis Opini Public. Jogjakarta ; Pelangi Aksara.

Flanagan, R. dan Norman, G. 1993. Risk Management and Construction. Cambridge : University Press.

Godfrey, P.S., Sir William Halcrow and Partners Ltd. 1996. Control of Risk A Guide to Systematic Management Of Risk from Construction. Wesminster London : Construction Industry Research and Information Association (CIRIA).

Halpin, D. W and Woodhead, R. W., 1998," Construction Management", John Wiley \& Sons, Canada.

Indah P.R dan Andi T.T. 2014. "Analisis Risiko Produktivitas Tenaga Kerja Terhadap Kinerja Waktu Proyek Pada Bangunan Bertingkat" (Jurnal). Depok; Universitas Gunadarma

Michael H. Walizer \& Paul L Wienir, (1987), Metode dan Analisis Penelitian:

Mencari Hubungan, Jilid 2, Erlangga, Jakarta.

Ni Putu Mega A. 2014. "Analisis Risiko Pelaksanaan Pembangungan Jalan Tol Benoa-Bandara-Nusa Dua” (Jurnal). Denpasar; Universitas Udayana 
Norken, I Nyoman. 2012, Manajemen Risiko Pada proyek Konstruksi di Pemerintah Kabupaten Jembrana. Jurnal ilmiah Teknik Sipil Universitas Udayana.

Nurcahyo B.S. 2017. “Analisis Manajemen Risiko Pada Proyek Pembangunan Jalan Tol (Studi Kasus Proyek Pembangunan Jalan Tol Solo-NgawiKertosono Ruas Ngawi-Kertosono Paket 3)" (Jurnal). Surakarta; Universitas Muhammadiyah Surakarta

Priyatno, Duwi. 2010. Teknik Mudah dan Cepat Melakukan Analisis Data Penelitian Dengan SPSS. Yogyakarta: Gava Media.

Peraturan Pemerintah Republik Indonesi, Nomor 15 Tahun 2005, Tentang Jalan Tol.

RSNI-T-XX-2008, Standar geometri jalan bebas hambatan untuk jalan tol

Ruslan, Rosady. 2003. Metode Penelitian Public Relation dan Komunikasi. Jakarta; PT. Raja Grafindo Persada.

Sandhyavitri, dkk. 2013. "Analisis Risiko Jalan Tol Tahap Pra Konstruksi (Studi Kasus: Jalan Tol Pekanbaru - Dumai)" (Jurnal). Pekanbaru; Universitas Riau.

Setiawan, dkk. 2014. "Analisis Manajemen Risiko Pada Proyek Pembangunan Jalan Tol Cisumdawu (Studi Kasus : Development of Cielunyi - Sumedang Dawuan Toll Road Phase 1)" (Jurnal). Garut; Sekolah Tinggi Teknologi Garut

Sitinjak J.R.T dan Sugiarto. 2006. LISREL. Yogyakarta : Graha ikmu.

Sugiyono. 2004. Metode Penelitian Kuantitatif, Kualitatif dan R\&D. Bandung: Alfabeta.

Thompson, P.A. dan Perry, J.G. 1991. Engineering Construction Risk. London : Thomas Telford Ltd.

Trisaputra, Herry. 2017. Manfaat Pembangunan jalan tol JORR 2. Jakarta : https://finance.detik.com/berita-ekonomi-bisnis/3473583/membentang-110km-ini-manfaat-pembangunan-tol-jorr-2

Vaughan, E. J. 1978. Fundamental of Risk and Insurance. Second Edition. New York. John Willey \& sons, Inc.

Wirawan, Nata, 2001, Cara Mudah Memahami Statistik Deskiptif \& Inferensia, Denpasar: Penerbit Keraras Emas

Wiyono, Bambang Budi. 2001. Statistik Pendidikan: Buku Bahan Ajar Mata Kuliah Statistik. Malang: FIP UM

Zainuddin. 2014. “Analisa Faktor Risiko Pada Proyek Konstruksi Jalan Raya (Studi Kasus; Proyek Pembangunan Jalan Perdesaan - Bojonegoro)" (Jurnal). Bojonegoro; Universitas Bojonegoro. 